\title{
Korean Learners' Metacognition in Reading Using Think-Aloud Procedures with a Focus on Regulation of Cognition
}

\author{
Hyang-Il Kim ${ }^{1}$ \& Kyung-Ae $\mathrm{Cha}^{2}$ \\ ${ }^{1}$ Department of Teacher Education, Hankuk University of Foreign Studies, Korea \\ ${ }^{2}$ Graduate School of TESOL, Hankuk University of Foreign Studies, Korea \\ Correspondence: Kyung-Ae Cha, Graduate School of TESOL, Hankuk University of Foreign Studies, Seoul, \\ 130-792, Korea. Tel: 82-10-2078-3177. E-mail: kacha@hufs.ac.kr
}

\author{
Received: February 17, 2015 Accepted: March 18, 2015 Online Published: May 28, 2015 \\ doi:10.5539/elt.v8n6p178 URL: http://dx.doi.org/10.5539/elt.v8n6p178
}

\begin{abstract}
The primary goal of this study was to explore the changes that four Korean university students made in their regulation of cognition during reading processes. The students were trained using explicit reading strategy instruction based on the CALLA model. To this end, first, metacognition was framed and categorized by the definition from Baker and Brown (1984) and, second, a scoring scale for measuring the readers' regulation of cognition was developed based on the study by Block (1992) to examine and trace any changes in their regulation processes. For data analyses, the participants' think-aloud protocols were used. The results indicate that there were marked changes in the frequencies of their regulation processes over time. Specifically, the students' overt strategic and regulatory behaviors in a regulation process showed more flexibility and organization toward the end of the strategy training. This study suggests that students would benefit from being provided with sufficient time for practice in order to build effective regulation of cognition in reading processes and that the teacher should understand the complex nature of the regulation processes that students go through. In addition, think-aloud procedures as an instructional tool for effective strategy training was shown to be a worthwhile technique in the classroom.
\end{abstract}

Keywords: metacognition, regulation, reading strategy instruction

\section{Introduction}

The research in L1/L2 reading supports the significant role of metacognition in learning (Anderson, 2008; Baker, 2002; Baker \& Brown, 1984; Block, 1992; Schraw \& Dennison, 1994; Malcolm, 2009; Schraw \& Moshman, 1995). Reading research has suggested that successful readers tend to read strategically as active agents to fulfill their goals based on metacognition which fosters learners to become more self-regulated readers (Grabe, 2009; Hudson, 2007; Zhang, 2010). Effective regulation promotes reading comprehension (Anderson, 1991; Baker, 2002; Grabe, 2009).

Strategy intervention studies have contributed to revealing the effectiveness of such training on successful reading through improving metacognition (Aghaie \& Zhang, 2012; Auerbach \& Paxton, 1997; Dhieb-Henia, 2003; Dreyer \& Nel, 2003; Kim \& Cha, 2014; Macaro \& Erler, 2008). They identify metacognition as a key factor that affects successful reading as it aids not only critical and practical reflection, but also aids in evaluation of thinking processes (Anderson, 2008). However, research has not provided profound insights into learners' metacognition with a clear theoretical framework. In addition, many of the reading strategy intervention studies offer informative findings about learners' changes in awareness and behaviors of metacognition based on the numeric data gathered from learners' self-rated questionnaires after intervention (Aghaie \& Zhang, 2012; Dreyer $\&$ Nel, 2003; Macaro \& Erler, 2008). Thus, we do not have much information about the qualitative effects of reading strategy training on learners' metacognitive regulation during reading processes. Therefore, this study aims to explore the changes in four Korean university learners' regulation of cognition as identified by Baker and Brown (1984) in their reading processes using think-aloud procedures during a 15-week reading strategy training. 


\section{Review of Literature}

\subsection{Regulation of Cognition}

Amid the plethora of definitions of metacognition that do not clearly distinguish between the mental activities and overt motor behaviors as identified by Dörnyei and Skehan (2003), Baker and Brown (1984) defined metacognition as consisting of two constructs-knowledge about cognition and regulation of cognition. They explained that the first one involves a reader's knowledge about cognitive resources, compatibility, and learning situation, and it corresponds to mental activities; while the other encompasses self-regulatory mechanisms which are used to solve ongoing problems and is related to overt motor behaviors. Their definition reveals that metacognition has separable domains of mental activities and overt motor behaviors during a reading process. This study finds the definition by Baker and Brown (1984) a suitable framework to explore a more in-depth and extensive understanding of each construct under metacognition. Specifically, the second construct, regulation of cognition, was mainly explored in this study.

Learners who have a high level of metacognition tend to plan ahead, employ specific strategies to suit their reading goal, monitor through regulating and redirecting strategies to accomplish the goal, and evaluate the strategy use (Hudson, 2007). Therefore, many researchers appear to agree that regulation of cognition involves three executive processes; planning, monitoring, and evaluation (Harris, Santangelo, \& Graham, 2010; McCormick, 2003; Phakiti, 2008; Schraw, 1998) which display overt motor behaviors of regulation.

First, planning includes the selection of suitable strategies and the allocation of cognitive resources to achieve a goal (Schraw, 1998). Second, monitoring refers to checking on-line comprehension or performance; involving evaluating a comprehension problem, or error, and double-checking comprehension (Phakiti, 2008). McCormick (2003) refers to this as regulation. Many studies have focused on monitoring as a main contributor to successful reading due to its regulatory mechanisms (Block, 1992; Brown \& Baker, 1984; Casanave, 1988; Yang, 2002, 2006), and it has also been categorized as a late developing skill (Schraw, 1998; Schraw \& Moshman, 1995). The last process is evaluation which indicates the actions used in appraising past and current actions or performance (Phakiti, 2008). Urqhart and Weir (1998) maintained that evaluation helps readers interact more actively with texts which may yield more accurate comprehension.

In an important study by Block (1992), she presented and divided a monitoring process into three stages-evaluation of comprehension (problem recognition), action (strategic planning or action / solution attempt), and checking the action. She observed that monitoring is generated by evaluating or recognizing a problem. Through this, a reader starts monitoring as an active processor, engaging in strategic planning, deciding the selections of appropriate strategies, and making attempts at a solution. In the checking stage, the solution is evaluated and, sometimes revised when necessary with effective strategy use. The three executive processes of regulation mentioned above are well manifested in Block's (1992) explanation of a process, which can, as McCormick (2003) noted, be called a regulatory process. Through analyzing the participants' regulation processes according to these three underlying processes, she found that both native and ESL students who read at an advanced level showed similar regulatory processes which were mostly complete and efficient, while the less proficient readers failed to show such processes. Her study indicates a student's proficiency level significantly matters in terms of the quality of regulation processes.

Despite the general findings of learners' strategic behaviors in reading, it is still unclear what changes appear during strategy training in regulation of cognition based on the precise definition by Baker and Brown (1984). More specifically, little is known about the specific changes in overt strategic behaviors shown in the three executive processes of regulation of cognition caused by strategy training. Therefore, this study will examine the participants' strategic behaviors in regulatory processes based on a scale developed from the study by Block (1992). The findings are expected to identify specific changes in regulation that the learners' go through during their reading processes.

\subsection{Think-Aloud Procedures}

In identifying cognitive processes, researchers are required to find means that allow for the observation of what are normally invisible actions. Many studies have employed concurrent think-aloud procedures as a tool to capture learners' invisible cognitive processes such as the strategic behaviors of learners' cognitive processes (Aghaie \& Zhang, 2012; Block, 1992). In addition, Swain (2006) argued that think-alouds were seen as a research methodology which develops learner's cognitive processes. Think-alouds have been used as an instructional tool to help learners build comprehension-monitoring abilities with some success (Baumann, Jones, \& Seifert-Kessell, 1993; McKeown \& Gentilucci, 2007; Oster, 2001), however, it needs to be noted that McKeown and Gentilucci (2007) reported that only intermediate level readers had positive results from using 
think-aloud procedures. Further, despite some concerns like unnaturalness and doubts in the degree of capturing information (Henk, 1993), there is support for the usefulness of think-aloud procedures with statistical evidence that learners' performances are not influenced by the procedures (Leow \& Morgan-Short, 2004). For these reasons, think-aloud procedures were carefully implemented as an instructional and research tool in this study.

\subsection{Reading Strategy Training in an EFL Setting}

Researchers have placed an emphasis on 'explicitness' in strategy training (Hudson, 2007). Explicit strategy training generally provides direct explanation about topic strategies focusing on the knowledge of strategy use such as what strategies are, and when, how, and why to use them, followed by a teacher's think-aloud modelling (Aghaie \& Zhang, 2012; Baumann et al., 1993; Bereiter \& Bird, 1985; Dewitz, Jones, \& Leahy, 2011; McKeown \& Gentilucci, 2007). As was indicated in the study by Baumann et al. (1993), it helps develop learners' metacognitive awareness for regulation.

Learners can become more effective and self-regulated readers, often, through explicitly designed instructional models in such training. The CALLA (The Cognitive Academic Language Learning Approach) which involves five sequential stages - preparation, presentation, practice, evaluation, and expansion - is an example of such a training program and was devised by Chamot and O'Malley (1994). It holds four practical propositions regarding its instructional aspects. First, mentally active learners are better learners. Second, strategies can be taught. Third, transferring learned strategies into a new task is possible. Forth, learning strategies are effective in facilitating academic language learning. These four propositions correspond to the purpose of this study, in that this study aims to help learners become more active regulators in their reading processes through strategy training, expanding the acquired strategic knowledge into use in a new task as independent readers, and eventually at promoting their reading competence. Therefore, the CALLA model was found to be the most appropriate for the explicit strategy training in this study.

Many studies have reported the positive effects of explicit strategy training. Aghaie and Zhang (2012) performed four months of training based on CALLA with 80 Iranian high school students. The experimental group outperformed the control group in reading, showing a strong correlation between strategy instruction and reading performance. They also reported an increase in the use of metacognitive strategies after the intervention. A longitudinal reading strategy instruction study by Macaro and Erler (2008) attempted to examine any changes in the strategy use of 62 students over 14 months. After the intervention, the experimental group performed better on comprehension tests and had clear changes in strategic behaviors through using more 'text-engagement' strategies. They argued that their participants became better orchestrators in using strategies with the help of the instruction. However, their findings are limited to showing only such specific changes. These studies are meaningful studies which highlight the positive roles of strategy instruction, however, they are restricted in that they only examine its effects from mostly quantitative results. It is also crucial to understand the changes in learner's strategy use within the qualitative research framework as well. Therefore, this study is motivated to provide an investigation of qualitative elements and the findings are expected to step forward to examine the influence of reading strategy training on learners' regulation of cognition as one of the two distinguishable constructs in metacognition. Specifically, this study attempted to answer the following two questions:

1) What changes did the Korean students who were selected for this study make in their frequency of regulatory process use?

2) What changes did they make in the regulatory processes used while reading?

\section{Method}

\subsection{Participants}

The profiles of the four participants in this study based on their interviews are presented in Table 1. They were in their third year in a South Korean university majoring in pre-pharm medical science. They had been studying in preparatory courses to apply for pharmaceutical college. The four students were chosen through purposeful sampling (Merriam, 2009), and taught separately from their original class. The four criteria were considered for selection. First, they had high motivation to develop their reading skills to obtain a high score on an internationally authorized English test (i.e., TOEFL or TOEIC) to enhance their application for pharmaceutical college. Second, their reading proficiency level was considered important to avoid linguistic threshold issues which note a minimum level of L2 language competence required for effective use of strategies (Carrell, 1991; Grabe \& Stroller, 2002) and think-aloud procedures (McKeown \& Gentilucci, 2007). As the TOEIC RC scores (Table 1) indicate, Mina scored 295, noticeably lower than the others, whereas Daehong scored 390, Youngsang 395, and Boyoung 375. Despite the discrepancy between the scores of Mina and the other three, all were 
identified as intermediate readers when consulting the four reading scoring rubrics of the TOEIC offered by ETS Global (2012), as their scores were seated in the two middle ranges - more specifically second and third, Mina as intermediate and the others as high-intermediate. Another criterion for the selection was that they were considered as being in a similar learning environment that controlled for other variables. All four participants did not have experience learning English abroad and similarly mentioned that their time for individual English learning was limited at the time. Lastly, they joined the study willingly.

Table 1. Summary of four participants' profile

\begin{tabular}{|c|c|c|c|}
\hline Name & Gender & $\begin{array}{l}\text { TOEIC } \\
\text { RC score }\end{array}$ & Reading traits \\
\hline Daehong & M & $390 / 495$ & $\begin{array}{l}\text { A pursuer of the big picture. Daehong tended to read in a top-down fashion } \\
\text { since he found this way easy to comprehend a text. He described that he } \\
\text { was quite good at getting the gist of a text when reading. }\end{array}$ \\
\hline Youngsang & M & $395 / 495$ & $\begin{array}{l}\text { An applier of life experience. Youngsang stated that he tried to relate his } \\
\text { background knowledge to a reading text for effective reading } \\
\text { comprehension. He thought that his main problem in reading was low } \\
\text { degree of concentration. }\end{array}$ \\
\hline Mina & $\mathrm{F}$ & $295 / 495$ & $\begin{array}{l}\text { An anxious reader. Mina demonstrated nervousness while reading due to } \\
\text { lack of confidence. According to her, the first thing she did was to look at } \\
\text { the title and the length of a text to gain information about what and how } \\
\text { much she had to read. }\end{array}$ \\
\hline Boyoung & $\mathrm{F}$ & $375 / 495$ & $\begin{array}{l}\text { An optimistic reader. Boyoung believed she recently found that her ability } \\
\text { to find the main idea of a text was weakened due to lack of reading time. } \\
\text { However, she believed that she could improve the skill soon with practice. }\end{array}$ \\
\hline
\end{tabular}

Note. The TOEIC RC scores were collected in the beginning of the strategy training.

\subsection{Research Instruments}

\subsubsection{Think-Aloud Protocols}

A major research instrument of this study was think-aloud protocols. They were expected to provide the data which show the changes in regulation and control of the participants' reading processes in terms of strategy use. To avoid the possibility of skepticism towards, and awkwardness with the new technique, its introduction was provided in week 2 , followed by time for practice. The participants were encouraged to stop reading a text occasionally and externalize their internal thoughts in their L1 or L2. They could read a text either aloud or silently to minimize interruptions and according to their preference.

Their think-alouds were audio-recorded individually from week 3 to week 14 and were transcribed verbatim. Each participant produced 12 think-aloud protocols, but only 9 were used for data analysis. The first two protocols from week 3 and 4 were excluded following the recommendation of Dörnyei (2007) as the participants required time to get used to the new technique which may have affected the data. During the 7th week protocols were not used due to different text lengths unlike those in other weeks. The protocols collected on week 5, 6, and 8 were grouped as the 1 st data collection period, those on week 9,10 , and 11 as the $2^{\text {nd }}$ data collection period, and those on week 12,13 , and 14 as the $3^{\text {rd }}$ data collection period. Considering that the data collection had been performed from week 3 to week 14, the second half of the data collection started from the 9th week. Therefore, the data collected from week 9 onwards (the data from the 2 nd and 3 rd data collection periods) were compared with those from the 1st period to trace any changes in terms of regulation of cognition shown in their reading processes.

\subsection{Data Collection}

The study was conducted over 15 weeks from March to June in 2013. The class met once a week for a general reading lesson followed by explicit reading strategy training. Each training session took 90 minutes. In week 1 , the outline of the strategy training was offered and the general purpose of the study was introduced. In the following week, think-aloud procedures were introduced and practiced. The actual strategy training commenced from week 3 to 14 and the participants' think-aloud data and pair discussions were recorded accordingly. The 
individual interviews were conducted in week 2 and 13. In week 15, the participants reviewed and discussed the roles of strategies.

\subsection{Reading Strategy Training Using Think-Aloud Procedures}

A major goal of reading strategy training was to help learners become more strategic readers (Baker, 2002). The training can be considered a collaborative program due to the shared responsibility of using strategies effectively between instructors and the students. Following the suggestion of Schraw (1998), the students as well as the teacher, participated in modeling their reading processes using think-aloud to their pairs. Paired-student modeling ought to assist learners in becoming more autonomous and self-regulated readers in a collaborative fashion. The participants were offered opportunities to model and observe think-alouds from week 11 under the teacher's guidance as the participants had become accustomed to think-aloud procedures and the teacher modeling. The decision for paired-student modeling was also determined to be plausible through the analysis of their think-aloud protocols by the researcher. In addition, it was partly out of concern for the "honeymoon effect" - of losing their enthusiasm in the new way of learning as time passes (Taylor, Stevens, \& Asher, 2006, p. 239).

A repertoire of 13 reading strategies was selected for this training through reviewing the related literature (Afflerbach, Pearson, \& Paris, 2008; Baker \& Brown, 1984; Baumann et al., 1993; Grabe, 2009; Jiang \& Grabe, 2007; Nuttall, 1996). The list of these strategies is attached in the Appendix. One or two of the topic strategies from the repertoire were focused on each week during the training session. However, it is important to note that an array of useful strategies for reading processes including topic strategies were shown during the teacher modeling, and not all strategies were explicitly taught. Through exemplary application of effective orchestration of strategies during a natural reading process, the instructor introduced helpful strategies indirectly but specifically in a well-harmonized manner. Even in pair-discussions, the students were encouraged to discuss the strategies that they employed and their effectiveness, along with topic strategies.

\subsubsection{The Five Stages}

Each lesson of the strategy training was structured on the instructional sequence frame of the CALLA as illustrated in Figure 1. Stage one-preparation - offered the participants to discuss the need for helpful strategies to build positive attitudes and willingness to use strategies to aid their comprehension. It was intended to provide the opportunities to reflect on their own usage of strategies. In stage two-presentation, explicit elaboration of a target strategy was provided followed by teacher modelling in think-aloud. The following stage offered an opportunity to practice the target strategy independently with the information gained from the previous stage. The participants were encouraged to use other helpful strategies. Particularly, an effective combination of strategies was emphasized. The time for an individual think-alouds was between 10 and 12 minutes. In stage four-evaluation, the participants in pairs discussed and evaluated their strategy use, focusing on how they handled comprehension difficulties. During the last stage, expansion, the teacher led a group discussion regarding strategy use and encouraged the use of strategies for later use.

From week 11 to 14 , as stated previously, there was a change in stage two-presentation; the participants modelled in pairs instead of the teacher. The explicit elaboration of a topic strategy and indirect learning from the previous teacher modeling made the student modeling possible. Their partner was encouraged to provide feedback on pair modeling.

\subsubsection{Strategy Training Materials}

In all, 11 long and 6 short texts were used for the program. The Appendix provides the information of all materials - topics, word counts, and readability levels. The texts were chosen from Reading Spectrum and designed for college level readers with various topics in informative expository texts. Gunning's fog index (available at www.readabilityformulas.com) was used to gauge the readability level of a text. The score of the materials for this study was 11.9 on average which correlated as 'hard to read'- these do not include the short passages. 
Table 2. Scoring scale for a regulatory process

\begin{tabular}{lllll}
\hline No. & Stages & Contents & \multicolumn{1}{l}{ Scoring } \\
\hline 1 & Evaluation & Problem recognition or Confusion/Comprehension failure & 1 \\
& & Strategic plan/action & None & 0 \\
& & & Exist & 1 \\
2 & \multirow{3}{*}{ Action for the solution } & & None & 0 \\
& & Solution attempt & Wrong & 1 \\
& & Correct & 2 \\
& & & None & 0 \\
3 & \multirow{3}{*}{ Checking the solution } & Checking the outcome of the action & Wrong & 1 \\
& & & Correct & 2 \\
\hline
\end{tabular}

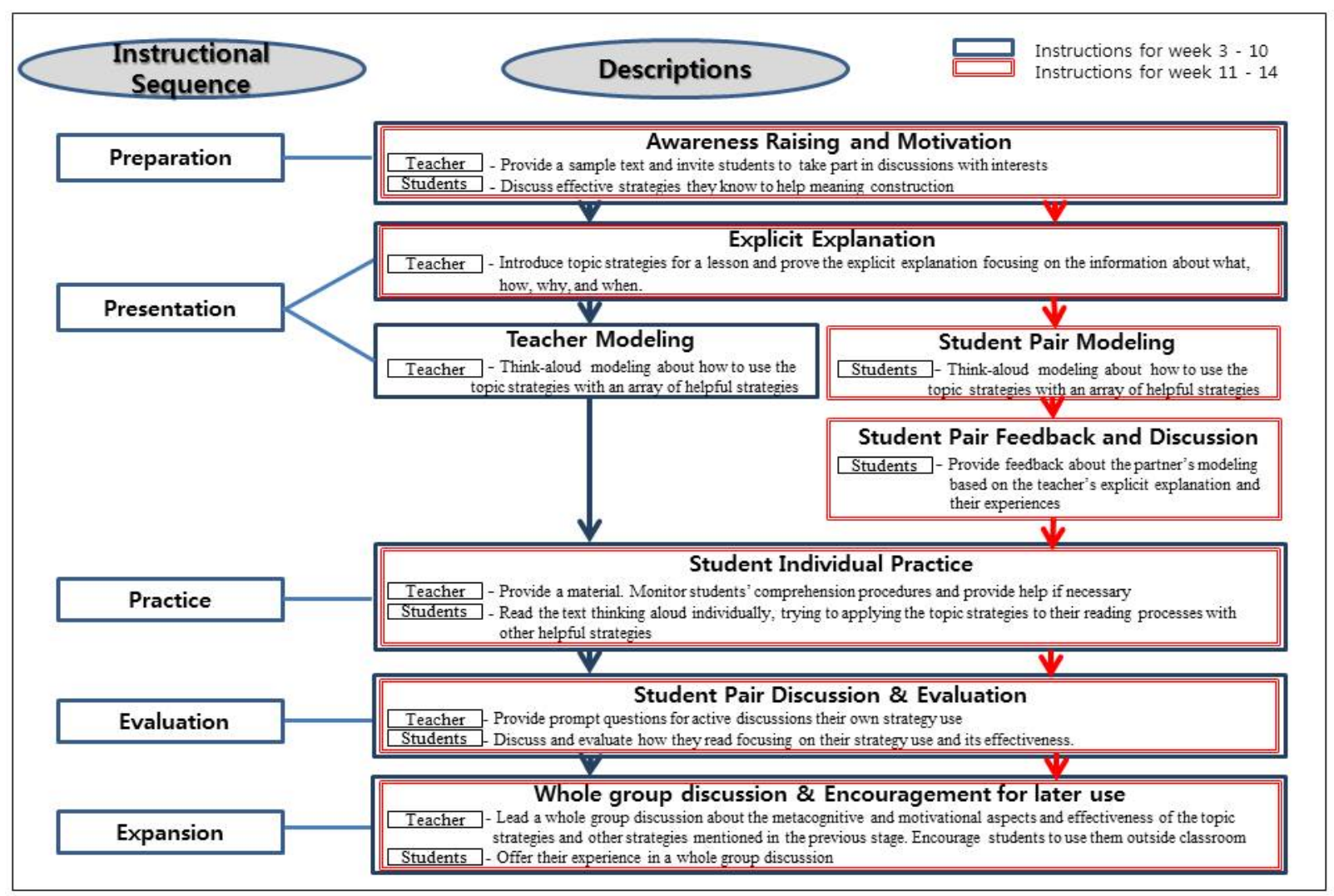

Figure 1. Instructional design for reading strategy training based on the CALLA model

\subsection{Methods for Data Analysis}

Under the construct of regulation of cognition, the patterns of the participants' regulation processes at the word level were scrutinized to trace any changes over the course of the program. For the data analysis, a scoring scale with three stages (Table 2) was developed from the study by Block (1992). According to the scale, readers get one point by evaluating or recognizing a problematic word in the first stage. In the second stage, they get one more point when making a strategic plan or action. Additionally, they obtain one or two points according to its correctness when attempting a solution. In the case of checking their solution attempts in stage 3, one or two more points are added depending on its correctness. Macaro (2001) maintains that successful readers tend to solve problems holistically and persistently unlike less successful readers, which usually results in a longer engagement with a text when handling problems. Therefore, this study finds that the longer and the more accurately they are engaged in a regulatory process, the higher the scores they will get according to this scale. 
This scoring scale aimed to reflect learners' active regulation and the accuracy of their reading comprehension. The reading strategies in the think-aloud protocols were identified through mainly consulting the coding index of Phakiti (2008). To ensure reliability of the analysis, peer checking (Dörnyei, 2007) was conducted by the co-author who is specialized in the study of reading strategies. Disagreements were resolved through discussion

\section{Results and Discussion}

\subsection{Changes in the Frequencies of a Regulation Process}

As was illustrated in Table 2, a determinant in counting the occurrences of a regulation process (RP) was reader's evaluation, or recognizing a problem. Table 3 demonstrates the 7 types of a RP analyzed in the participants' think-aloud protocols. Types 4, 5, 6, and 7 were categorized into a complete set of a RP since they involved all three stages, whereas the other types were considered as incomplete.

Table 3. The seven types of a regulation process found in the participants' think-aloud protocols

\begin{tabular}{|c|c|c|c|c|c|c|c|}
\hline $\begin{array}{l}\text { Types } \\
\text { of RPs }\end{array}$ & 1 & 2 & 3 & 4 & 5 & 6 & 7 \\
\hline \multirow{5}{*}{ Stages } & \multirow[t]{5}{*}{ Evaluation } & Evaluation & Evaluation & Evaluation & Evaluation & Evaluation 1 & Evaluation \\
\hline & & Action & Action 1 & Action & Action 1 & Action 1 & Action 1 \\
\hline & & & Action 2 & Checking & Action 2 & Evaluation 2 & Action 2 \\
\hline & & & & & Checking & Checking & Checking \\
\hline & & & & & & & Double-checking \\
\hline
\end{tabular}

The total frequencies of RPs over the three data collection periods were 9, 13, and 30, in chronological order (Table 4). Table 4 illustrates the marked changes in the patterns of the student's RPs at the word level. It shows that by the $3^{\text {rd }}$ collection period, the participants recognized more problems in a text and were involved in RPs more actively in order to solve their problems, engaging in more advanced stages. This indicates that they articulated strategic plans and attempted to take action to solve problems more frequently and checked them in their reading processes in the final data collection period. Notably, except for two cases in Daehong's data, the others had no incidences of a complete RP (all three stages) in the $1^{\text {st }}$ and $2^{\text {nd }}$ periods. However, the frequencies of such an RP appeared in the data in the 3rd data collection period, excluding Mina.

Table 4. The combined frequencies of a regulation process at the word level

\begin{tabular}{|c|c|c|c|c|c|c|c|c|c|c|c|c|c|c|c|}
\hline Time & $1^{\mathrm{st}}$ & erio & & & & $2^{\text {nd }}$ & peric & & & & $3^{\text {rd }}$ & berio & & & \\
\hline Frequency & $\begin{array}{l}\mathscr{D} \\
\mathbb{\Xi} \\
\tilde{W} \\
0 \\
0 \\
0\end{array}$ & 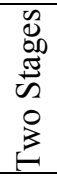 & 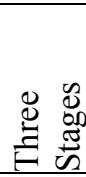 & $\frac{\infty}{a}$ & $\begin{array}{l}\mathscr{0} \\
\stackrel{0}{0} \\
\tilde{D} \\
\mathscr{n}\end{array}$ & 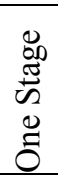 & 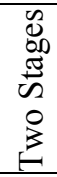 & 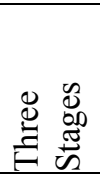 & $\frac{\infty}{\frac{\pi}{\sigma}}$ & $\begin{array}{l}\mathscr{U} \\
\stackrel{0}{0} \\
\tilde{D} \\
\mathscr{n}\end{array}$ & 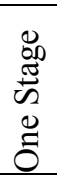 & 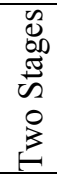 & 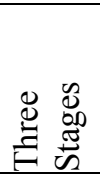 & $\frac{\infty}{\frac{\pi}{\sigma}}$ & $\begin{array}{l}\tilde{U} \\
\tilde{0} \\
\tilde{D}\end{array}$ \\
\hline Daehong & 1 & 1 & 0 & 2 & 6 & 2 & 4 & 2 & 8 & 26 & 4 & 4 & 1 & 9 & 26 \\
\hline Youngsang & 1 & 3 & 0 & 4 & 12 & 0 & 0 & 0 & 0 & 0 & 3 & 5 & 2 & 10 & 25 \\
\hline Mina & 0 & 0 & 0 & 0 & 0 & 2 & 1 & 0 & 3 & 6 & 2 & 2 & 0 & 4 & 10 \\
\hline Boyoung & 2 & 1 & 0 & 3 & 6 & 0 & 2 & 0 & 2 & 7 & 1 & 4 & 2 & 7 & 22 \\
\hline Total & 4 & 5 & 0 & 9 & 24 & 4 & 7 & 2 & 13 & 39 & 10 & 15 & 5 & 30 & 83 \\
\hline
\end{tabular}

Note. 'One stage' refers to the RP with the first stage of Evaluation. 'Two stages' indicates the RP with two stages involving 'Evaluation' and 'Action for the solution'. 'Three stages' refers to the RP with the all three stages involving 'Evaluation', 'Action for the solution', and 'Checking the solution'.

Bear in mind that the participants' regulation or control in their reading process was reflected in their scores, which suggests that the quality of all the participants' RPs improved over time. As shown in Table 4, Daehong's scores indicate that he had rapid development in the quality of RPs, acquiring 26 points in the $2^{\text {nd }}$ and $3^{\text {rd }}$ periods as compared to 6 points in the 1st period. Youngsang and Boyoung showed dramatic changes in the $3^{\text {rd }}$ period, 
scoring 25 and 22 points respectively. It is also of note that Mina showed a steady increase in scores, 6, 7, and 10 . However, unlike the others, Mina did not reach the third stage as a complete RP and her RP scores did not show considerable changes over time. This finding suggests that there were differences in the RPs of the three participants and Mina and the result seems to be affected by the gaps in these participants' reading proficiency. Although they were all categorized as intermediate level readers, Mina was specifically intermediate while the others were high-intermediate, as shown in Table 1. In other words, reading proficiency appears to be a factor that influences the degree of development in RPs. This finding is consistent with Block's (1992) study which revealed learners with different reading proficiency levels engaged in different qualities of RPs. This study further suggests that learners' reading proficiency levels may influence the development of an RP when receiving strategy training.

\subsection{Changes in a Regulation Process at the Word Level}

The incidences of an RP at the word level identified in the participants' think-aloud data were scrutinized to detect any further changes. Examining their think-aloud protocols, the percentage of the incidences that the participant only recognized problems (the first stage) without any further stages decreased from $44 \%(n=4)$ in the 1 st period to $31 \%(n=4)$ and $33 \%(n=10)$ in the two latter periods respectively. Table 5 , the excerpt of Daehong's think-aloud protocols, is an example of such an incidence. As seen in Table 5, Daehong found the word 'sedatives' problematic, but no actions were taken to solve the problem in his protocols.

Table 5. Think-aloud excerpt (Daehong/Week $5 / 1^{\text {st }}$ period)

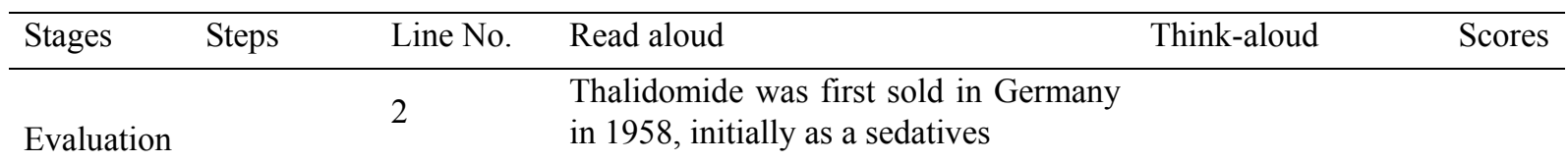

What is 'sedatives'? 1

Strategic

Action plan/action Solution $\quad$ None 0

Checking

None

0

Note. 'Read-aloud' indicates what the participants read from the text. 'Think-aloud' refers to what a reader said to oneself. 'Line No.' is the line numbers used in the original think-aloud protocols.

Further, it was discovered that in the $1^{\text {st }}$ data collection period, three participants' solution attempts advanced to the second stages of an RP and were mostly made from quite basic and simple use of a strategy, such as using knowledge of root words and context clues. Among the five incidences of the second stage found in the $1^{\text {st }}$ period (see Table 4), Boyoung used root-word knowledge $(\mathrm{n}=1)$ and Daehong used context clues in the text $(\mathrm{n}=1)$ - shown in Table 5. Youngsang had three solution attempts during this period, using root word knowledge $(n=2)$ and context clues of a text $(n=1)$. In other words, the four participants' solution attempts in the earlier days of data collection were dependent on relatively simple linguistic knowledge and strategic behaviors. Youngsang's think-aloud excerpt in Table 6 is an example of the incidences.

Table 6. Think-aloud excerpt (Youngsang/Week $7 / 1^{\text {st }}$ period)

\begin{tabular}{|c|c|c|c|c|c|}
\hline Stages & Steps & Line No. & Read aloud & Think-aloud & Scores \\
\hline \multirow{2}{*}{ Evaluation } & & 9 & 'half-bred'... & & \\
\hline & & & & I do not know the word, 'half-bred'... & 1 \\
\hline \multirow[t]{2}{*}{ Action } & $\begin{array}{l}\text { Strategic plan/action } \\
\text { (using root word } \\
\text { knowledge) }\end{array}$ & 10 & & Two words... 'half' and 'bred'... & 1 \\
\hline & Solution attempt & & & Well, it seems like mixed breed. & 2 \\
\hline Checking & & & & None & 0 \\
\hline
\end{tabular}


Youngsang recognized the word, 'half-bred', as problematic in Line 9 shown Table 6. His strategic action shows that he utilized his root-word knowledge, 'half' and 'bred' to solve his problem, which was successful, and he thus received 4 points as compared with 1 point in Table 5. Similarly, the three other participants' solution attempts in the earlier days of data collection were also dependent on relatively simple linguistic knowledge and strategic behaviors.

Not unlike the data collected in the $1^{\text {st }}$ collection period, the participants did not reach the third stage of RPs in the following period; except for Daehong who showed impressive changes in his RPs from the $2^{\text {nd }}$ collection period (see Table 4) when is two RPs were complete attempts. His think-aloud excerpt, Table 7, illustrates his monitoring and regulating process for his vocabulary problem, 'pandemic'. It is important to note that he went through two action stages to make a correct solution attempt. In addition, he checked his solution twice, showing prudent engagement in his regulation process for accuracy. For example, in his first action stage, he scanned a few words of each paragraph to collect information about the context and attempted to fill the gap based on the contextual information (Line 2) but his first solution attempt was incorrect due to insufficient information. The second stage shows how he was able to successfully relate 'pandemic' to disease through synthesizing the key information into a concise concept after reading three paragraphs. It is interesting to see his checking stage as he carefully evaluated his earlier solution attempt as incorrect, saying 'pandemic' is not history but a kind of disease around the end of a text. After reading the whole text, he went back to the title and double-checked to confirm his solution again, resulting in 10 points. Through such checking procedures, he had the opportunities not only to accurately solve his problem, but also to check his understanding of an overall text.

Table 7. Think-aloud excerpt (Daehong/Week 10/2 ${ }^{\text {nd }}$ period)

\begin{tabular}{|c|c|c|c|c|c|}
\hline Stages & Steps & Line No. & Read-aloud & Think-aloud & Scores \\
\hline \multirow[b]{2}{*}{ Evaluation } & & 1 & $\begin{array}{l}\text { Humanity in the face of } \\
\text { pandemics }\end{array}$ & & \\
\hline & & & & $\begin{array}{l}\text { Humanity that is seen from } \\
\text { pandemics. What does } \\
\text { 'pandemic' mean? }\end{array}$ & 1 \\
\hline \multirow{3}{*}{ Action 1} & & 2 & & Looking at each paragraphs, & 1 \\
\hline & $\begin{array}{l}\text { Strategic } \\
\text { plan/action } \\
\text { (Scanning) }\end{array}$ & & $\begin{array}{l}\text { The number of Spanish... } \\
\text { In the eyes of the Aztecs... } \\
\text { Historically... The history } \\
\text { of human beings... }\end{array}$ & & \\
\hline & $\begin{array}{l}\text { Solution } \\
\text { attempt }\end{array}$ & & & $\begin{array}{l}\text { Then.... this story may be about } \\
\text { history. 'Pandemic' is something } \\
\text { like...the word related to history. }\end{array}$ & 1 \\
\hline \multirow{3}{*}{ Action 2} & $\begin{array}{l}\text { Strategic } \\
\text { plan/action } \\
\text { (Synthesizing } \\
\text { information) }\end{array}$ & 11 & & $\begin{array}{l}\mathrm{Hmm} . . . \text { it seems that the biggest } \\
\text { (threat) of humans is ... diseases. }\end{array}$ & 1 \\
\hline & & 12 & flu pandemic? & & \\
\hline & $\begin{array}{l}\text { Solution } \\
\text { attempt }\end{array}$ & & & $\begin{array}{l}\text { Then, is 'pandemic' a disease, } \\
\text { isn't it? }\end{array}$ & 2 \\
\hline \multirow{3}{*}{ Checking } & & 17 & & Moreover, ........ & \\
\hline & $\begin{array}{l}\text { (Using } \\
\text { context clues) }\end{array}$ & & $\begin{array}{l}\text {...... we must listen to the } \\
\text { nature's warning and be } \\
\text { both vigilant... }\end{array}$ & & \\
\hline & & & & $\begin{array}{l}\text { Then, 'pandemic' is something } \\
\text { like a virus or a kind of disease, } \\
\text { rather than history. }\end{array}$ & 2 \\
\hline $\begin{array}{l}\text { Double } \\
\text { checking }\end{array}$ & $\begin{array}{l}\text { (reading } \\
\text { title) }\end{array}$ & 18 & & $\begin{array}{l}\text { Hmm... The title is... Humanity } \\
\text { seen from a pathogenic } \\
\text { perspective. I think it is right. }\end{array}$ & 2 \\
\hline
\end{tabular}


Examining his excerpt helps find several new strategic and regulatory behaviors that were not identified in his data collected in the $1^{\text {st }}$ period and in the other participants' data in both $1^{\text {st }}$ and $2^{\text {nd }}$ periods. The first is the use of various options from a wider pool of strategies. Daehong's strategy use seemed to become more varied, suggesting that his strategy use was drawn from a larger repertoire of strategies. Other new strategic behaviors in his RP present active and dynamic regulation in the process of problem solution with an effective orchestration of strategies. According to Macaro and Erler (2008), orchestration of a set of strategies requires an unceasing metacognitive decision-making process that involves monitoring, evaluating, and re-choosing a set of strategies. In short, metacognition is reflected in the reader's attempts to configure a cluster of strategies flexibly to achieve their reading goals. This new pattern suggests substantial changes in the regulation of Daehong's reading processes. With such new strategic behaviors in his RP, he was able to solve the problem successfully and accurately.

As mentioned earlier, it was not until the $3^{\text {rd }}$ data collection period that such complete and active RPs were observed from three of the participants - Daehong, Youngsang, and Boyoung-Mina unlike the others, did not produce any complete RP, even in the $3^{\text {rd }}$ period - as seen in Table 4 . However, one of the data collected in the $3^{\text {rd }}$ period (Table 8 ) showed that the active regulation of her RP was similar to those of the other participants'. As seen in Table 8, she actively involved two action stages for a correct answer, which amounted to 6 points. For her first action, she made a wild guess relating the problematic word, 'abortion' to 'crime' from the context clue, a word, 'legal' (Line 14). She went further taking the second action and bridged the gap successfully based on obtaining enough information from strategic behaviors such as paying attention to a discourse marker, 'however' saying 'there comes a contrary story', and using a context clue, 'Abortions take away the lives of unborn children.' (Line 19). Although she missed stage 3, the checking stage, her regulation of this RP seemed clearly different from her earlier attempts.

Table 8. Think-aloud excerpt (Mina/Week $13 / 3^{\text {rd }}$ period)

\begin{tabular}{|c|c|c|c|c|c|}
\hline Stages & Steps & Line & Read aloud & Think-aloud & Scores \\
\hline Evaluation & & 6 & & $\begin{array}{l}\text { Prohibited in 1966. What? } \\
\text { 'Abo...rtion'? What is it? }\end{array}$ & 1 \\
\hline \multirow[t]{2}{*}{ Action 1} & $\begin{array}{l}\text { Strategic } \\
\text { plan/action } \\
\text { (using } \\
\text { discourse } \\
\text { markers, } \\
\text { context clues) }\end{array}$ & 14 & $\begin{array}{l}\text { Abortions became legal } \\
\text { national wide }\end{array}$ & & 1 \\
\hline & $\begin{array}{l}\text { Solution } \\
\text { attempt }\end{array}$ & & & $\begin{array}{l}\text { 'Abortion'. It is the word related to } \\
\text { crime. Sexual abuse }\end{array}$ & 1 \\
\hline \multirow{4}{*}{ Action 2} & $\begin{array}{l}\text { Strategic } \\
\text { plan/action }\end{array}$ & 18 & $\begin{array}{l}\text { However, there is a strong } \\
\text { voice of opposition... }\end{array}$ & & 1 \\
\hline & $\begin{array}{l}\text { (using } \\
\text { discourse }\end{array}$ & & & $\begin{array}{l}\text { There comes a contrary story. } \\
\text { What for? }\end{array}$ & \\
\hline & $\begin{array}{l}\text { markers, } \\
\text { context clues) }\end{array}$ & & $\begin{array}{l}\text { Abortions take away the } \\
\text { lives of unborn children }\end{array}$ & & \\
\hline & $\begin{array}{l}\text { Solution } \\
\text { attempt }\end{array}$ & 19 & & $\begin{array}{l}\text { Naktae* (abortion). Maybe it is } \\
\text { Naktaebub (abortion laws). }\end{array}$ & 2 \\
\hline
\end{tabular}

Note. When a student said the exactly same word in Korean toward the unknown word, the word was recorded in Korean pronunciation in italic and the English meaning was provided in the bracket to avoid any confusion.

A more sophisticated regulation process can be found in Youngsang's think-aloud excerpt with the same word, 'abortion', in Table 9. It shows a complete progression of an RP and suggests that he was deeply and actively involved in his RP in order to fix his vocabulary problem, 'abortion', in a more orchestrated manner. For example, he attempted to use context clues to guess as the meaning of 'abortion' preliminarily and correctly (Line 9). In Line 13, he logically connected the pre- and post-information from the discourse marker 'however' 
which led him to check his solution attempt. He double-checked it by assertively retrieving his background knowledge about President Obama's health insurance reform and abortion issues in Line 15. These strategic behaviors were not found in most participants' data collected in the $1^{\text {st }}$ and $2^{\text {nd }}$ data collection periods. Such effective regulation during an RP reflects higher level metacognition that is mainly found in the 3rd data collection period. It appears that such orchestration of a set of strategies as a goal in his RP positively influenced the accuracy of his reading comprehension.

Table 9. Think-aloud excerpt (Youngsang/Week 13/3 ${ }^{\text {rd }}$ period)

\begin{tabular}{|c|c|c|c|}
\hline Stages & Steps & Line No. & Read aloud \\
\hline Evaluation & & 4 & prohibited abortion.... \\
\hline \multirow{3}{*}{ Action } & $\begin{array}{l}\text { Strategic } \\
\text { plan/action } \\
\text { (Using } \\
\text { context clues) }\end{array}$ & 9 & $\begin{array}{l}\text { to legalize abortions... } \\
\text { stating }\end{array}$ \\
\hline & $\begin{array}{l}\text { Solution } \\
\text { attempt }\end{array}$ & & \\
\hline & & & $\begin{array}{l}\text { legalize } . . . \\
\text { abortion.... }\end{array}$ \\
\hline Checking & $\begin{array}{l}\text { (using } \\
\text { discourse } \\
\text { markers) }\end{array}$ & 13 & $\begin{array}{l}\text { However, there is a strong } \\
\text { voice of opposition because } \\
\text { abortions take away the } \\
\text { lives of unborn children. }\end{array}$ \\
\hline
\end{tabular}

Hmm... this means it is illegal, 1 but made it legal.

Is it Naktae* (abortion)?

'Abor..tion'? What is 'abortion'? 1

Checking

Anyway, she attempted to make it legal....

However, there is a strong lives of unborn children.

It seems that it is right, Naktae (abortion)... There comes a story about a life in the following. 2 Here's the word, 'however'.

The health insurance reform recently pursed by (Using U.S. President Barak $\begin{array}{lllll}\text { Double } & \text { background } & 15 & \text { O.S. President Barak } \\ \text { checking } & \text { knowledge) } & & \begin{array}{l}\text { Obamas faced } \\ \text { difficulties because of the }\end{array}\end{array}$ abortion issue.

Yes, Obama and his abortion 2 issue. I think it is right.

Another complex and enhanced set of an RP is shown in Boyoung's excerpt in Table 10. It is interesting that she went through both evaluation and action stages twice in search for the solution in this excerpt. She attempted to associate the word, 'curse' with a negative connotation and was able to retrieve the meaning successfully (Line 2), but it appears that she was not satisfied with the intial guess due to a lack of supporting evidence, saying, "Curse... Still cannot have the glimmer of it." (Line 3). It contrasts with one of the common patterns of poor readers, attempting guesses, as reported by Macaro (2001). She continued reading the text and was able to relate her background knowledge of a myth that she had previously read which assisted her in arriving at the right meaning through obtaining more information gathered through continuing reading (Line 12). She did not forget to check her answer by going back to the title (Line 13). 
Table 10. Think-aloud excerpt (Boyoung/Week 14/3 ${ }^{\text {rd }}$ period)

\begin{tabular}{|c|c|c|c|c|c|}
\hline Stages & Steps & $\begin{array}{l}\text { Line } \\
\text { No. }\end{array}$ & Read aloud & Think-aloud & Scores \\
\hline & & 1 & $\begin{array}{l}\text { Not a curse, but still } \\
\text { weighty issue... }\end{array}$ & & \\
\hline \multirow{3}{*}{ Evaluation 1} & & & & Hm... 'Curse'? What does it mean? & 1 \\
\hline & & & $\begin{array}{l}\text { However, still weighty } \\
\text { issue }\end{array}$ & & \\
\hline & & & & Still an important issue.... & \\
\hline \multirow[t]{3}{*}{ Action 1} & $\begin{array}{l}\text { Strategic } \\
\text { plan/action } \\
\text { (Associating } \\
\text { the image of a } \\
\text { word) }\end{array}$ & 2 & & $\begin{array}{l}\text { As I remember, 'curse' has } \\
\text { negative meaning...... }\end{array}$ & 1 \\
\hline & $\begin{array}{l}\text { Solution } \\
\text { attempt }\end{array}$ & & & $\begin{array}{l}\text { 'Spell' } \ldots \text {.... 'a bad spell', } \\
\text { something like this. Anyway... }\end{array}$ & 2 \\
\hline & & 3 & & $\begin{array}{l}\text { According the Greek Myth, you } \\
\text { can meet this person, Erysichthon, }\end{array}$ & \\
\hline \multirow[t]{3}{*}{ Evaluation 2} & & & $\begin{array}{l}\text { Who was cursed } \\
\text { with........ }\end{array}$ & & \\
\hline & & & & $\begin{array}{l}\text { Hm... The one who suffered from } \\
\text { starvation... 'Curse'... Still cannot } \\
\text { have the glimmer of it. }\end{array}$ & 1 \\
\hline & $\begin{array}{l}\text { Strategic } \\
\text { plan/action } \\
\text { (Using } \\
\text { background } \\
\text { knowledge, } \\
\text { context clues) }\end{array}$ & 7 & $\begin{array}{l}\text { The enraged goddess } \\
\text { cursed him with } \\
\text { insatiable hunger so } \\
\text { that he could never.... } \\
\text { be full. }\end{array}$ & & \\
\hline \multirow{6}{*}{ Action 2} & & & & $\begin{array}{l}\text { Uh... the enraged goddess (made) } \\
\text { him never be full, never be } \\
\text { satisfied... }\end{array}$ & \\
\hline & & 11 & & $\begin{array}{l}\text { Ah! Now I got it. I know what } \\
\text { myth is. }\end{array}$ & 1 \\
\hline & & & $\begin{array}{l}\text { He made free himself } \\
\text { the terrible curse ...... }\end{array}$ & & \\
\hline & & 12 & & $\begin{array}{l}\text { Made him hungry... always have } \\
\text { hunger... a... (She) spelled him. } \\
\text { Anyway, she did this kind of thing. }\end{array}$ & \\
\hline & $\begin{array}{l}\text { Solution } \\
\text { attempt }\end{array}$ & & & From his death, he... uh... & \\
\hline & & & & $\begin{array}{l}\text { Jeo... (Cur...) ... Ah!... Jeoju } \\
\text { (Curse). Right Jeoju!. Jeoju was } \\
\text { ended. }\end{array}$ & 2 \\
\hline Check & $\begin{array}{l}\text { (Reading } \\
\text { title) }\end{array}$ & 13 & & $\begin{array}{l}\text { So, the title means, it is still } \\
\text { important issue, not Jeoju (a } \\
\text { curse). }\end{array}$ & 2 \\
\hline
\end{tabular}


Continuing reading after identifying a problem, and withholding judgment in order to search for correct meaning, as was observed in Boyoung's excerpt, is one of the comprehension monitoring strategies (Paris, Wasik, \& Turner, 1991). This encouraged her to employ more strategies consciously and flexibly to deal with her comprehension difficulties reading back and forth in the text as an active agent, which is commonly noticed in advanced readers (Baumann et al., 1993). Such flexibility makes readers more dynamically and actively engaged in their RPs that are not linear at all. It can be said that such active regulation of reading processes was developed with the help of strategy training.

The findings of an RP at the word level suggest. First, the quantitative findings indicate that the participants evaluated more vocabulary problems as time passed. Importantly, it was not until the 3rd data collection period that most participants engaged in the complete set of an RP, which showed a quite slow development process. This confirms the assertions of Schraw (1998) and Schraw and Moshman (1995) who argued that such a process is a late developing skill. Second, the findings of the qualitative analysis demonstrated that they were able to address problems, sometimes revising and checking their solutions successfully, going through more stages - sometimes involving a few action or checking stages. Importantly, the participants used more types of strategies in a more flexible and orchestrated manner based on enhanced metacognitive decision-making rather than relying on simple linguistic and contextual cues. This is regarded as a feature associated with more successful readers (Block, 1992; Hudson, 2007; Macaro, 2001; Macaro \& Erler, 2008). The participants' control or regulation of RPs was clearly and noticeably enhanced and made more complex in a more effective and orchestrated manner. Third, although it was not the focus of this study, it was found that proficiency level may affect the development of an RP as seen in Mina's data which did not show a complete set of an RP even in the 3rd data collection period.

\section{Conclusion}

The purpose of this study was to explore Korean university students' changes in their regulation of cognition using the metacognition framework outlined by Baker and Brown (1984). To this end, a scale for a regulation process was developed based on the study by Block (1992). The thorough analysis of think-aloud protocols made it possible to trace the changes due to explicit strategy training.

The results demonstrated that the participants evaluated more vocabulary problems over time and there were marked changes in the frequency of complete sets of RPs at the word level in around the end of strategy training. Importantly, the enhanced regulation and meaningful changes in their RPs were identified, which can be found only through qualitative analysis. Although the participants showed quite different patterns of RPs, their strategic behaviors and regulation appeared in a more flexible and orchestrated manner, showing more engagement as an active regulator in reading processes. It was also found that a learner's proficiency level may affect the usage of RPs.

Despite some limitations regarding generalizability of a small scale study, this study holds some implications for effective strategy training according to these findings. This study found that explicit strategy training using think-aloud procedures as an instructional tool was effective in promoting the participants' regulation of cognition. It is crucial to encourage and motivate learners to employ strategies and evaluate their use for successful reading by providing them with time for practice and evaluation in a collaborative atmosphere as well as explicit information regarding helpful strategies. In addition, the teacher should understand the complex nature of an RP so that they can carefully design strategy training on the consideration that learners' proficiency levels may affect the degree of the development in an RP.

\section{Acknowledgments}

This study is based on a section of the first author's unpublished dissertation (Kim, 2014) which was completed under the supervision of the corresponding author. This article is substantially revised from the original dissertation.

\section{References}

Afflerbach, P., Pearson, P. D., \& Paris, S. G. (2008). Clarifying differences between reading skills and reading strategies. Reading Teacher, 61(5), 364-373. http://dx.doi.org/10.1598/RT.61.5.1

Aghaie, R., \& Zhang, L. J. (2012). Effects of explicit instruction in cognitive and metacognitive reading strategies on Iranian EFL students' reading performance and strategy transfer. Instructional Science, 40(6), 1063-1081. http://dx.doi.org/10.1007/s11251-011-9202-5

Anderson, N. J. (1991). Individual differences in strategy use in second language reading and testing. The Modern Language Journal, 75(4), 460-472. http://dx.doi.org/10.1111/j.1540-4781.1991.tb05384.x 
Anderson, N. J. (2008). Metacognition and good language learners. In C. Griffiths (Ed.), Lessons from good language learners (pp. 99-109). Cambridge, UK: Cambridge University Press. http://dx.doi.org/10.1017/CBO9780511497667

Auerbach, E. R., \& Paxton, D. (1997). "It's not the English thing": Bringing reading research into the ESL classroom. TESOL Quarterly, 31(2), 237-261. http://dx.doi.org/10.2307/3588046

Baker, L. (2002). Metacognition in comprehension instruction. In C. Block, \& M. Pressley (Eds.), Comprehension instruction: Research-based best practices (pp. 77-95). New York, NY: Guilford Press.

Baker, L., \& Brown, A. L. (1984). Metacognitive skills and reading. In P. D. Pearson, M. M. Kamil, R. Barr, \& P. Mosenthal (Eds.), Handbook of research in reading (pp. 353-395). New York, NY: Longman.

Baumann, J. F., Jones, L. A., \& Seifert-Kessell, N. (1993). Using think alouds to enhance children's comprehension monitoring abilities. The Reading Teacher, 47(3), 184-193.

Bereiter, C., \& Bird, M. (1985). Use of thinking aloud in identification and teaching of reading comprehension strategies. Cognition and Instruction, 2(2), 131-156. http://dx.doi.org/10.1207/s1532690xci0202_2

Block, E. L. (1992). See how they read: Comprehension monitoring of L1 and L2 readers. TESOL Quarterly, 26(2), 319-343.

Carrell, P. L. (1991). Second language reading: Reading ability or language proficiency? Applied Linguistics, 12(2), 159-179. http://dx.doi.org/10.1093/applin/12.2.159

Casanave, C. P. (1988). Comprehension monitoring in ESL reading: A neglected essential. TESOL Quarterly, 22(2), 283-302. http://dx.doi.org/10.2307/3586937

Chamot, A. U., \& O'Malley, J. M. (1994). The CALLA handbook: Implementing the cognitive academic language learning approach. New York, NY: Longman.

Dewitz, P., Jones, J., \& Leahy, S. (2011). Comprehension strategy instruction in core reading programs. Reading Research Quarterly, 44(2), 102-126. http://dx.doi.org/10.1598/RRQ.44.2.1

Dhieb-Henia, N. (2003). Evaluating the effectiveness of metacognitive strategy training for reading research articles in an ESP context. English for Specific Purposes, 22(4), 387-417. http://dx.doi.org/10.1016/S0889-4906(03)00017-6

Dörnyei, Z. (2007). Research methods in applied linguistics. Oxford, UK: Oxford University Press.

Dörnyei, Z., \& Skehan, P. (2003). Individual differences in second language learning. In C. J. Doughty, \& M. H. Long (Eds.), The handbook of second language acquisition (pp. 589-630). Oxford: Blackwell Publishing. http://dx.doi.org/10.1002/9780470756492.ch18

Dreyer, C., \& Nel, C. (2003). Teaching reading strategies and comprehension within a technology-enhanced learning environment. System, 31(3), 349-365. http://dx.doi.org/10.1016/S0346-251X(03)00047-2

ETS Global. (2012). TOEIC listening and reading scores descriptors and European CEFR levels. Retrieved from http://www.etsglobal.org/content/download/768/12037/version/3/file/TOEIC+L\%26R+DescriptorsMAR089-LR.pdf

Grabe, W. (2009). Reading in a foreign language. Cambridge, UK: Cambridge University Press.

Grabe, W., \& Stoller, F. L. (2002). Teaching and researching reading. Harlow, UK: Longman.

Harris, K. R., Santangelo, T., \& Graham, S. (2010). Metacognition and strategy instruction in writing. In H. S. Waters, \& W. Schneider (Eds.), Metacognition, strategy use, \& instruction (pp. 226-256). New York, NY: Guilford.

Henk, W. A. (1993). New directions in reading assessment. Reading and Writing Quarterly, 9(1), 103-119. http://dx.doi.org/10.1080/1057356930090106

Hudson, T. (2007). Teaching second language reading. Oxford, UK: OUP.

Jiang, X., \& Grabe, W. (2007). Graphic organizers in reading instruction: Research findings and issues. Reading in a Foreign Language, 19(1), 34-55.

Kim, H. (2014). A case study of Korean learners' metacognitive knowledge systems changes through explicit reading strategy instruction using think-aloud procedures (Unpublished doctoral dissertation). Hankuk University of Foreign Studies. Seoul, Korea.

Kim, H., \& Cha, K. (2014). A study of Korean university students' metacognitive knowledge through reading 
strategy instruction. Modern English Education, 15(1), 71-95.

Leow, R. P., \& Morgan-Short, K. (2004). To think aloud or not to think aloud: The issue of reactivity in SLA research methodology. SSLA, 26(1), 35-57.

Macaro, E. (2001). Learning strategies in second and foreign language classrooms. London, U.K: Continuum.

Macaro, E., \& Earler, L. (2008). Raising the achievement of young-beginner readers of French through strategy instruction. Applied Linguistics, 29(1), 90-119. http://dx.doi.org/10.1093/applin/amm023

Malcolm, D. (2009). Reading strategy awareness of Arabic-speaking medical students studying in English. System, 37(4), 640-651. http://dx.doi.org/10.1016/j.system.2009.09.008

McCormick, C. B. (2003). Metacognition and learning. In W. M. Reynolds, \& G. E. Miller (Eds.), Handbook of psychology: Educational psychology (Vol. 7, pp. 79-102). New York, NY: John Wiley \& Sons. http://dx.doi.org/10.1002/0471264385.wei0705

McKeown, R. G., \& Gentilucci, J. L. (2007). Think-aloud strategy: Metacognitive development and monitoring comprehension in the middle school second-language classroom. Journal of Adolescent \& Adult Literacy, 51(2), 136-147. http://dx.doi.org/10.1598/JAAL.51.2.5

Nuttall, C. (1996). Teaching reading skills in a foreign language. London, UK: Heinemann.

Oster, L. (2001). Using the think-aloud for reading instruction. The Reading Teacher, 55(1), 64-69.

Paris, S. G., Wasik, B. A., \& Turner, J. C. (1991). The development of strategic readers. In R. Barr, M. L. Kamil, P. Mosenthal, \& P. D. Pearson (Eds.), Handbook of reading research (Vol. 2, pp. 609-640). New York, NY: Longman.

Phakiti, A. (2008). Construct validation of Bachman and Paler's (1996) strategic competence model over time in EFL reading tests. Language Testing, 25(5), 237-272. http://dx.doi.org/10.1177/0265532207086783

Schraw, G. (1998). Promoting general metacognitive awareness. Instructional Science, 26(1/2), 113-125. http://dx.doi.org/10.1023/A:1003044231033

Schraw, G., \& Dennision, R. S. (1994). Assessing metacognitive awareness. Contemporary Education Psychology, 19(4), 460-475. http://dx.doi.org/10.1006/ceps.1994.1033

Schraw, G., \& Moshman, D. (1995). Metacognitive theories. Educational Psychology Review, 7(4), 351-371. http://dx.doi.org/10.1007/BF02212307

Sheorey, R., \& Mokhtari, K. (2001). Differences in the metacognitive awareness of reading strategies among native and non-native readers. System, 29(4), 431-449. http://dx.doi.org/10.1016/S0346-251X(01)00039-2

Swain, M. (2006). Verbal protocols: What does it mean for research to use speaking as a data collection tool? In M. Chalhoub-Deville, C. A. Chapelle, \& P. Duff (Eds.), Inference and generalizability in applied linguistics. Multiple perspectives (pp. 98-113). U.S.A: John Benjamins Publishing. $\mathrm{http}: / / \mathrm{dx}$.doi.org/10.1075/11lt.12.07swa

Taylor, A., Stevens, J. R., \& Asher, W. J. (2006). The effects of explicit reading strategy training on L2 reading comprehension. In J. M. Norris, \& L. Ortega (Eds.), Synthesizing research on language learning and teaching (pp. 213-245). Amsterdam, the Netherlands: John Benjamins. http://dx.doi.org/10.1075/11lt.13.11 tay

Urquhart, S., \& Weir, C. (1998). Reading in a second language: Process, product and practice. New York, NY: Longman.

Yang, Y. (2002). Reassessing readers' comprehension monitoring. Reading in a Foreign Language, 14(1), $18-42$.

Yang, Y. (2006). Reading strategies or comprehension monitoring strategies? Reading Psychology, 27(4), 313-343. http://dx.doi.org/10.1080/02702710600846852

Zhang, L. J. (2008). Constructivist pedagogy in strategic reading instruction: Exploring pathways to learner development in the English as a second language (ESL) classroom. Instructional Science, 36(2), 89-116. http://dx.doi.org/10.1007/s11251-007-9025-6

Zhang, L. J. (2010). A dynamic metacognitive systems account of Chinese university students' knowledge about EFL reading. TESOL Quarterly, 40(2), 320-353. http://dx.doi.org/10.5054/tq.2010.223352 


\section{Appendix}

Reading Materials and Target Strategies

\begin{tabular}{|c|c|c|c|c|c|}
\hline Week & Field & Topic & $\begin{array}{l}\text { Words } \\
\text { Count }\end{array}$ & $\begin{array}{l}\text { Gunning's Fog } \\
\text { Readability level }\end{array}$ & Target Strategy \\
\hline 3 & Medical & $\begin{array}{l}\text { Gender and the } \\
\text { Courts }\end{array}$ & 244 & Hard to read (13) & Self-questioning \\
\hline 4 & Medical & Medicine and poison & 206 & $\begin{array}{l}\text { Fairly easy to } \\
\text { read }(10.3)\end{array}$ & \multirow{2}{*}{$\begin{array}{l}\text { Relating textual } \\
\text { information using prior } \\
\text { knowledge }\end{array}$} \\
\hline 5 & Living things & $\begin{array}{l}\text { Food for thought for a } \\
\text { desolate land }\end{array}$ & 253 & Hard to read (11) & \\
\hline 6 & Living things & A cry for the Wolf & 323 & $\begin{array}{l}\text { Hard to read } \\
(11.5)\end{array}$ & $\begin{array}{l}\text { Predicting and verifying } \\
\text { using prior knowledge }\end{array}$ \\
\hline 7 & $\begin{array}{l}\text { Short texts (a } \\
\text { paragraph-length) } \\
\text { with various topics }\end{array}$ & $\begin{array}{l}\text { Environments, } \\
\text { Lucky charms, } \\
\text { Democracy, } \\
\text { Greek culture, } \\
\text { Protein, Antismoking } \\
\text { campaign }\end{array}$ & $\begin{array}{l}\text { Average } \\
134\end{array}$ & $\begin{array}{l}\text { Hard to read } \\
(10.2-13.3)\end{array}$ & $\begin{array}{l}\text { Recognizing the } \\
\text { structure of a paragraph } \\
\text { /Guessing words }\end{array}$ \\
\hline 8 & Psychology & $\begin{array}{l}\text { Little guys with great } \\
\text { stature }\end{array}$ & 199 & Hard to read (12) & Guessing words \\
\hline 9 & Health & Power paralyzed & 310 & $\begin{array}{l}\text { Fairly easy to } \\
\text { read }(10.3)\end{array}$ & Making inferences \\
\hline 10 & Medical & $\begin{array}{l}\text { Humanity in the face } \\
\text { of pandemics }\end{array}$ & 395 & $\begin{array}{l}\text { Hard to read } \\
(13.2)\end{array}$ & Analyzing the text \\
\hline & History & $\begin{array}{l}\text { Tattoos no longer } \\
\text { taboo }\end{array}$ & 376 & $\begin{array}{l}\text { Hard to read } \\
(12.7)\end{array}$ & \multirow[b]{2}{*}{$\begin{array}{l}\text { Recognizing } \\
\text { structures }\end{array}$} \\
\hline $11-12$ & Social & $\begin{array}{l}\text { Thousands of protest } \\
\text { over Bangladesh } \\
\text { deaths }\end{array}$ & 236 & Hard to read (13) & \\
\hline 13 & Social & $\begin{array}{l}\text { Wanted: babies, and } \\
\text { lots of them }\end{array}$ & 294 & $\begin{array}{l}\text { Hard to read } \\
(10.8)\end{array}$ & $\begin{array}{l}\text { Evaluating/Backtracking } \\
\text { and read on }\end{array}$ \\
\hline 14 & Social & $\begin{array}{l}\text { Not a curse, but still } \\
\text { weighty issue }\end{array}$ & 319 & $\begin{array}{l}\text { Hard to read } \\
(13.1)\end{array}$ & $\begin{array}{l}\text { Other strategies } \\
\text { (Paraphrasing, } \\
\text { summarizing, describing } \\
\text { mental images) }\end{array}$ \\
\hline
\end{tabular}

\section{Copyrights}

Copyright for this article is retained by the author(s), with first publication rights granted to the journal.

This is an open-access article distributed under the terms and conditions of the Creative Commons Attribution license (http://creativecommons.org/licenses/by/3.0/). 